\title{
Social Daydreaming and Adjustment: An Experience-Sampling Study of Socio-Emotional Adaptation During a Life Transition
}

\author{
Giulia L. Poerio ${ }^{1 *}$, Peter Totterdell ${ }^{1,2}$, Lisa-Marie Emerson ${ }^{1,2}$ and Eleanor Miles ${ }^{3}$ \\ ${ }^{1}$ Department of Psychology, University of York, York, UK, ${ }^{2}$ Department of Psychology, University of Sheffield, Sheffield, UK, \\ ${ }^{3}$ School of Psychology, University of Sussex, Brighton, UK
}

\section{OPEN ACCESS}

Edited by: John M. Zelenski,

Carleton University, Canada

Reviewed by:

Cristina Ottaviani,

Santa Lucia Foundation, Italy

Eve-Marie Blouin-Hudon,

Carleton University, Canada

${ }^{*}$ Correspondence:

Giulia L. Poerio

giulia.poerio@york.ac.uk

Specialty section:

This article was submitted to Personality and Social Psychology, a section of the journal

Frontiers in Psychology

Received: 19 October 2015

Accepted: 05 January 2016

Published: 21 January 2016

Citation:

Poerio GL, Totterdell P, Emerson L-M and Miles E (2016) Social

Daydreaming and Adjustment: An Experience-Sampling Study of Socio-Emotional Adaptation During a Life Transition. Front. Psychol. 7:13. doi: 10.3389/fpsyg.2016.00013
Estimates suggest that up to half of waking life is spent daydreaming; that is, engaged in thought that is independent of, and unrelated to, one's current task. Emerging research indicates that daydreams are predominately social suggesting that daydreams may serve socio-emotional functions. Here we explore the functional role of social daydreaming for socio-emotional adjustment during an important and stressful life transition (the transition to university) using experience-sampling with 103 participants over 28 days. Over time, social daydreams increased in their positive characteristics and positive emotional outcomes; specifically, participants reported that their daydreams made them feel more socially connected and less lonely, and that the content of their daydreams became less fanciful and involved higher quality relationships. These characteristics then predicted less loneliness at the end of the study, which, in turn was associated with greater social adaptation to university. Feelings of connection resulting from social daydreams were also associated with less emotional inertia in participants who reported being less socially adapted to university. Findings indicate that social daydreaming is functional for promoting socio-emotional adjustment to an important life event. We highlight the need to consider the social content of stimulus-independent cognitions, their characteristics, and patterns of change, to specify how social thoughts enable socio-emotional adaptation.

Keywords: daydreaming, mind wandering, socio-emotional adaptation, social cognition, social emotion, emotional inertia, loneliness, experience-sampling

\section{INTRODUCTION}

Throughout life, individuals must adapt to challenges in their environment, which may be minor such as daily hassles, or major such as life transitions and traumatic events (including the transition to university; Shaver et al., 1985). People show remarkable ability to adjust to significant life events (e.g., Frederick and Loewenstein, 1999; Bonanno, 2004) and often do so much faster than they anticipate (Gilbert et al., 1998). How do everyday thoughts help or hinder such adjustment? Cognitive theories of adjustment propose that the content of thinking predicts adaptive or maladaptive outcomes (e.g., Segerstrom et al., 2003; Watkins, 2008). However, these approaches overlook the social content of cognition, which is surprising because many events requiring adjustment are social in nature, and the cognitions associated with adjustment are therefore likely 
to be interpersonally focused. We address this gap and explore how everyday social thoughts in daydreams are related to the process of socio-emotional adjustment in the context of adaptation to a new environment, namely, young adults' first transition to university.

\section{Social Daydreaming}

When people are not thinking about or processing the external world, their attention turns inward toward selfgenerated information (e.g., reliving past experiences and formulating future plans). A substantial portion of daily life is occupied with such daydreaming activity; estimates indicate that this may be between 30 and 50\% of waking thought (Klinger and Cox, 1987; Killingsworth and Gilbert, 2010). Daydreams represent mental content that is stimulusindependent (i.e., based on memory rather than perception) and task-unrelated (i.e., unrelated to current activity; see Smallwood and Schooler, 2015). Although daydreams are stimulus-independent, their occurrence and content are often influenced by cues in the external environment, such as when certain smells or tastes conjure nostalgic daydreams of childhood. However, the stimulus-independency of daydreaming reflects that fact that, despite sometimes being triggered by stimuli in the external world, the object of attentional focus during daydreaming is internal rather than external. Daydreaming is sometimes considered synonymous with spontaneous thought (e.g., Christoff et al., 2004) but we take the view that daydreams can also be deliberate (e.g., Giambra, 1995; Seli et al., 2015) and the extent to which daydreams occur and develop deliberately or spontaneously is likely to be a key dimension upon which daydreams can vary.

Several investigations indicate that daydreams are predominately social in nature (i.e., involving the mental representation of others). A large-scale survey demonstrated that nearly three-quarters of daydreams frequently or always involved others (Mar et al., 2012), other people feature in $71 \%$ of daydreaming instances (Song and Wang, 2012), and content analysis of daydreams identifies other-related thoughts as a major thought flow dimension (Andrews-Hanna et al., 2013).

Given the frequency of social daydreaming it would seem likely to serve adaptive socio-emotional functions. Although early texts on daydreaming have speculated on the adaptive value of daydreaming for social relationships and well-being (e.g., Singer, 1966; Klinger, 1990), little empirical evidence exists to support these claims. We suggest that individuals' social daydreams are central to understanding how individuals adjust to social challenges. During times of social challenge, social daydreams reflect attempts to mentally address pertinent social goals and needs, but whether they do so effectively, and promote later adjustment, depends on the specific characteristics of daydreams (e.g., their emotional content and outcomes, their fanciful nature, and social content) and their dynamics. We review evidence for this proposal showing that (1) environmental challenges bias daydreaming content, (2) daydreaming characteristics predict (mal)adjustment, and (3) social daydreams have beneficial effects on socio-emotional well-being.

\section{Environmental Challenges Bias Daydreaming Content}

When people are faced with challenges in life, particularly emotionally significant ones, their thought flow is dominated by those events. Daydreaming content is biased in this way because daydreams are connected to an individual's current goals, needs, and desires. This relationship is articulated by Klinger's $(2009,2013)$ current concerns theory, which proposes that daydreaming content is dictated by an individual's current goal pursuits (i.e., desired end states). Daydreams occur when an individual encounters goal-relevant information in situations where overt action toward goals is not possible. Daydreams therefore allow mental progress toward relevant goals, which may involve processing and consolidating current goal pursuits, considering the possibilities and means to achieve them, as well as preparing for and motivating later action (Klinger, 2013).

The proposition that ongoing thought content is dictated by current concerns is supported by empirical studies showing that: daydreaming content and frequency is naturally related to individuals' important current life concerns and self-relevant goals (Klinger et al., 1980; Gold and Reilly, 1985; Baird et al., 2011; Stawarczyk et al., 2011) and that experimentally manipulating goals or needs biases daydreaming content toward mentally addressing those goals and needs (Antrobus et al., 1966; Kappes et al., 2012b; Stawarczyk et al., 2011).

\section{Thought Content Predicts (Mal)Adjustment}

Cognitive theories of adjustment propose that repetitive thinking predicts adjustment to environmental challenges (e.g., Segerstrom et al., 2003). Various forms of repetitive thought have been identified including worry, rumination, mental simulation, cognitive and emotional processing, and reflection (Watkins, 2008), which have both adaptive and maladaptive outcomes with respect to adjustment and well-being. Post-event cognitive processing (e.g., Bower et al., 1998; Calhoun et al., 2000), emotional processing (e.g., Manne et al., 2007; Hoyt et al., 2013) and reflective thinking (e.g., Burwell and Shirk, 2007; Eisma et al., 2014) predict successful adjustment following stressful events. However, other forms of repetitive thinking, notably rumination and worry, have been associated with negative outcomes in the context of adjustment (e.g., Ehlers et al., 1998; Holeva et al., 2002; Ito et al., 2003; Robinson and Alloy, 2003).

Attempts to integrate the seemingly contradictory effects of repetitive thought have resulted in dimensional approaches, which propose that the positive or negative effects of cognition on adjustment depend on its content (Segerstrom et al., 2003; Watkins, 2008). Several important dimensions have been identified: valence, purpose, and level of construal. Positively valenced repetitive thoughts tend to be associated with positive outcomes, especially when thoughts involve a searching purpose (i.e., exploring possibilities and understanding); negatively valenced repetitive thoughts tend to be associated with negative 
outcomes, especially when they involve a searching purpose and are abstract (Segerstrom et al., 2003, 2010, 2015; Watkins, 2008)

Similarly, The Content Regulation Hypothesis (Smallwood and Andrews-Hanna, 2013) states that the (mal)adaptive impact of daydreaming on psychological well-being depends on its content. For example, daydreaming may be associated with depression only when episodes are unintentional (Deng et al., 2014) or when thoughts are self-focused and indicative of negative rumination (Marchetti et al., 2014). Additionally, daydreams with a positive emotional content (Poerio et al., 2013), future time orientation (Ruby et al., 2013), and content of interest to the daydreamer (Franklin et al., 2013) have all been associated with positive emotional outcomes. Thus, rather than viewing repetitive thoughts or daydreams as inherently adaptive or maladaptive, their effects depend on the content of cognitions and context in which they occur.

Although dimensional approaches have helped to make sense of how thinking can have adaptive and maladaptive outcomes, they do not typically consider the social content of thought. As an exception, Segerstrom et al. (2003, Study 2) identified that repetitive thinking can vary to the extent that it is interpersonally or intrapersonally focused and found that the effects of negative repetitive thinking on depression were most pronounced when cognition was self- rather than other-focused (Segerstrom et al., 2003, Study 3). This finding dovetails with the consistent relationship observed between self-focused attention and negative affect (Mor and Winquist, 2002) and indicates that self-focused negative thinking is particularly detrimental. Although self-focused thinking may have negative outcomes, research has yet to fully document the effects of more otherfocused thinking on adjustment.

\section{Social Daydreams and Socio-Emotional Well-Being}

Although research has not yet examined how imagining others is related to adjustment, social daydreaming has been linked with positive effects on socio-emotional wellbeing, in particular, loneliness. Mar et al. (2012) found that although loneliness was associated with more social daydreaming, only the tendency to daydream about close others (versus non-close others) was associated with greater socioemotional well-being. This suggests that lonely individuals engage in more social daydreaming to counteract loneliness; however, only daydreaming about close others confers a socioemotional benefit, whereas daydreaming about non-close others may exacerbate loneliness. Likewise, research on imagined interactions-internal dialogs with real-life significant others (Edwards et al., 1988)-suggests the social daydreams of chronically lonely individuals may be indicative of a maladaptive response. Chronically lonely individuals report experiencing fewer, less satisfying, and more negative imagined interactions (Honeycutt et al., 1989) suggesting that loneliness may be exacerbated by a lack of positive social daydreaming and, by extension, that frequent and positive social daydreams may buffer against loneliness.
Studies examining the effects of individual social daydreams on momentary socio-emotional well-being also show that certain types of social daydreaming can regulate and shape emotional well-being. Poerio et al. (2015b) found that social, but not nonsocial, daydreams were associated with increased feelings of happiness, love, and connection with others. Interestingly, this association was only observed when participants were low in these feelings before daydreaming and when their daydreams involved close others implying that daydreams about close others may function to regulate social emotions. Consistent with this, directed daydreaming about close others has been shown to promote positive social feelings (connection, love, belonging) after induced loneliness (Poerio et al., 2015a) showing that social daydreaming can replenish feelings of interpersonal connection under conditions where belongingness has been threatened.

\section{Can Social Daydreams Naturally Enhance Socio-Emotional Adjustment?}

Although previous research is consistent with the proposal that positive characteristics of social daydreaming may promote socio-emotional adjustment, they are limited, because they do not examine social daydreaming during the process of adjustment. Cross-sectional research has examined the daydreams of individuals, who are currently adapted or maladapted (e.g., lonely or not) and measured supposedly stable and global daydreaming features. This assumes that individuals display consistent patterns of daydreaming over time, does not account for the dynamic nature of daydreaming, and cannot capture the process of adaptation over time. Adaptation is often examined as a state rather than a process (Luhmann et al., 2012) because crosssectional approaches typically examine predictors of adjustment (e.g., repetitive thinking) and levels of adjustment on a particular variable of interest (e.g., depression, loneliness) at the same single point in time. The problem with this approach is that associations (e.g., between daydreaming and loneliness) may be bi-directional or amenable to third-variable explanations, which highlights the need for prospective studies that examine daydreaming repeatedly over time. Although experimental designs have enabled consideration of daydreaming within a specific context (e.g., induced loneliness), daydreaming is artificially directed rather than spontaneously occurring and therefore does not capture the idiosyncratic and personally meaningful nature of daydreaming. Laboratory experiments are also only able to examine the short-term effects of daydreaming, which, again, cannot capture the process of adjustment over time. Adjustment is a temporal process, which means that to properly understand, how social daydreams are related to adjustment, it is necessary to capture repeated observations of daydreaming over time in a situation where adjustment is required.

In addition to examining daydreaming as a dynamic process it is also necessary to consider daydreaming as heterogeneous and measure the characteristics of daydreams. The previously reviewed literature suggests some important social daydreaming characteristics that might be expected to predict adjustment: their emotional outcomes (connection, loneliness, and positivity), valence, and the relationship quality between the daydreamer and 
the most central other person involved in the daydream. Other literature also suggests that the fanciful nature of daydreams may relate to adjustment because fanciful thinking has been previously associated with negative outcomes (e.g., Oettingen and Wadden, 1991; Kappes et al., 2012a).

Consistent with dimensional approaches, social daydreams per se should not predict adjustment, but their characteristics and patterns of change over time should. If social daydreams were part of an adaptive response then they should, over time, become more constructive. Specifically, they should be associated with more positive emotional outcomes (greater connection and positivity, and less loneliness), become more positively valenced, involve higher quality relationships, and become less fanciful. This pattern of constructive change over time should then predict later socio-emotional adjustment.

\section{The Present Study}

To capture the dynamic and heterogeneous nature of social daydreams over time and their relationship to adjustment, we used experience-sampling methodology to sample social daydreams during a period of naturally occurring adjustment. Life events offer opportunities to study adjustment, because they are episodes that involve a substantial change in an individual's daily routine and require a new behavioral response. We chose to examine social daydreaming during students' first transition to university because it is (1) a stressful life event that requires an adaptive response; it is reported as one of the most stressful periods of adjustment in life (Shaver et al., 1985) and is associated with increased psychological ill-health (e.g., Bewick et al., 2010) and (2) a time of socio-emotional challenge where social goals and emotions (e.g., preventing loneliness) are likely to be important, perhaps more so than academic or financial ones (Arthur and Hiebert, 1996; Bitsika et al., 2010), because moving to university disrupts existing social support networks and requires the formation of new relationships.

To examine, how social daydreaming was related to socioemotional adjustment during this transition, we measured the characteristics of social daydreams described above (i.e., emotional outcomes, valence, relationship quality, fanciful nature) twice daily for 1 month. We measured adjustment outcomes (loneliness and social adjustment to university) after 2 and 4 weeks of the study. We chose these measures to index adjustment at two time points in the study (although other outcomes indicative of adjustment such as subjective well-being or levels of depression might also have been warranted) due their relevance to the particular transition and the socio-emotional aspects of that transition, which was our main focus. The social adaptation to university scale measures the extent to which students feel that they have integrated socially to university life and is therefore directly relevant for capturing perceptions of social adjustment within the study context. The measurement of loneliness is an adjustment outcome consistent with previous daydreaming research and pertinent to the university transition because it has been identified as a commonly experienced feeling and issue for transitioning students, particularly in the first months of the transition (Cutrona, 1982; Shaver et al., 1985). The repeated measurement of social daydreaming and its characteristics enabled an examination of the temporal process of daydreaming during adjustment to university.

\section{Daydreaming Over Time}

We predicted that positive features of daydreaming would increase over time indicative of adjustment. However, we reasoned that because the process of adjustment is likely to first involve participants' reaction to the new environment followed by an adaptive response, evidence of positive change over time for social daydreams would be delayed. For this reason, we examined how social daydreams changed over time during the earlier and later stages of the transition separately. We expected social daydreams to show positive and constructive patterns of change in the last weeks (when students are adapting) but not the first weeks (when students are reacting). We also examined how feelings in general changed over time, specifically feelings of connection, positivity, and negativity. Like social daydreaming, we expected feelings to change over time, becoming increasingly positive, but only in the last weeks of the study.

\section{Emotional Inertia as an Index of Adjustment}

As additional evidence of the role of social daydreams in adjustment, we drew on the concept of emotional inertia. Emotional inertia describes resistance to emotional change over time and is thought to reflect psychological maladjustment (Kuppens et al., 2010). Emotional inertia can be indexed by the extent to which a person's current emotional state is predicted by their emotional state at a previous time point (i.e., the autocorrelation between successive measurements of emotional states). Evidence that high emotional inertia is indicative of a maladaptive response comes from studies demonstrating that emotional inertia predicts depression (Kuppens et al., 2012) and ill health (Wang et al., 2012). We reasoned that if social daydreams were linked to successful adjustment, then we would expect the emotional outcomes of daydreaming to show less evidence of inertia (i.e., show faster changes in the emotional outcomes of daydreams) in individuals who are currently socially maladjusted to the university transition (i.e., participants who report being less socially integrated within university than others).

\section{Social Daydreaming and Later Adjustment}

Based on daydreaming research, we also predicted that positive features of social daydreaming would predict better socioemotional adjustment. We used loneliness and social adaptation to university to index adjustment, and measured them after 2 (T1) and 4 (T2) weeks. If, as we propose, social daydreams promote socio-emotional adjustment, then the positive features of social daydreams should predict better adjustment at T2 controlling for $\mathrm{T} 1$.

\section{MATERIALS AND METHODS}

\section{Participants}

One hundred and three first year students at a UK university $\left(M_{\text {age }}=19.34, S D=2.34 ; 75\right.$ females $)$ were recruited to 


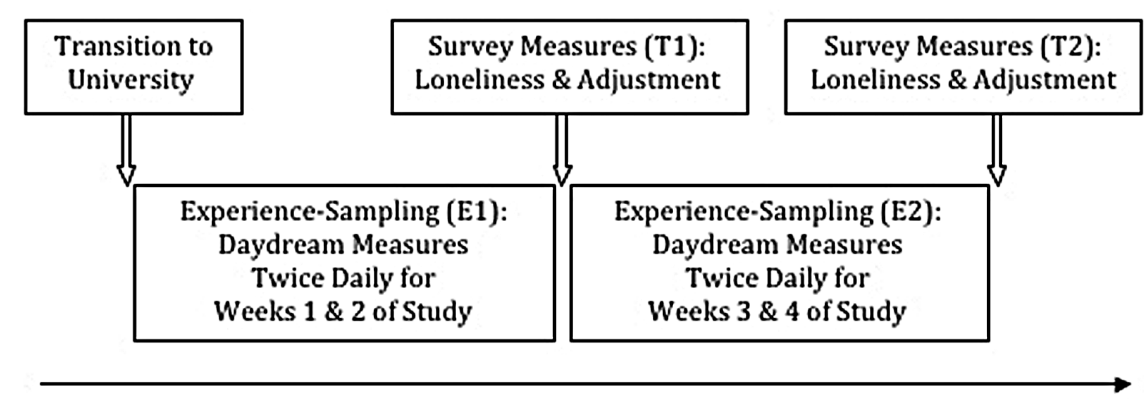

Study Period

FIGURE 1 | Study protocol.

the study, which was described as an investigation into first year undergraduates' thoughts and feelings. Sample size was based on recommendations that at least 100 groups at level2 (i.e., participants in the current study) should be used when analyzing data with multi-level structural equation modeling (Hox et al., 2010). Students were recruited at the start of their first year of university via email advertisement, flyers, word of mouth, and participant referrals. All first year undergraduate students could take part on the condition that they had access to a smartphone with Internet access for the duration of the study. Participants started the study during the first 3 weeks of the first semester of university (September 22nd, 2014 October 13th, 2014), which comprised of introduction week and the first two teaching weeks of the semester. In exchange for participation, psychology undergraduates (59\%) were given course credits; non-psychology students were given $£ 10$ worth of food vouchers. Ethical approval for the study was obtained from the University of Sheffield Psychology ethics committee and informed consent was obtained from all participants before the study began.

\section{Procedure}

Participants attended a group training session where they were given written and verbal instructions for the study. Daydreaming was defined as stimulus-independent and task-unrelated thought. Social/non-social daydreams were defined as daydreams where another (real or imaginary) person or people are/are not involved. Participants were given a demonstration of the experiencesampling method, a verbal explanation of the meaning and response to each questionnaire item and instructions on how to complete the survey.

Figure 1 summarizes the study design timeline. The first experience-sampling period (E1) began the day after the training session and the second experience-sampling period (E2) began 2 weeks later. Overall, participants were signaled twice daily over 28 days via text message to their smartphones and reported on their current or most recent social daydream by answering an online questionnaire using their smartphone. Participants received the signals at random times each day between 10:00 and 22:00 (one between 10:00 and 16:00, the other between 16:00 and 22:00 with at least $1 \mathrm{~h}$ between consecutive signals).
Randomization of signals was used to prevent anticipation and to sample daydreams across a range of times and daily activities. Previous experience-sampling approaches in the daydreaming literature have signaled participants more frequently but for a shorter period of time (e.g., 8 and 12 signals daily for 7 days, Kane et al., 2007; Poerio et al., 2013). Decisions about sampling protocols in experience-sampling designs typically reflect a balance between the frequency of signals, study duration, and time to complete measures in order to minimize participant burden (Christensen et al., 2003). Given our interest in change over a relatively long period of time (28 days) we employed a low sampling frequency rate (twice daily) so as not to place excessive demands on participants. Participants also completed two online questionnaires, prompted via email, at the end of the first 2 weeks of the study (T1) and at the end of the study (T2), which measured loneliness and social adaptation to university over the past 2 weeks.

\section{Experience-Sampling Measures Daydreaming}

Participants answered: "Right before you were signaled, were you daydreaming?" ("Yes" = 1, "No" = 0). If they answered affirmatively, then they answered: "Did your daydream involve another person or people?" ("Yes" = 1, "No" = 0). When participants did not experience a social daydream immediately prior to signaling, they were instructed, "Please think about your last daydream that involved another person or people." Participants then answered the questions described below in a randomized order.

\section{Daydreaming Characteristics}

Participants rated how their daydream made them feel compared to before it for three measures of emotion using 7-point response scales ( $1=$ much less, $4=$ no different, $7=$ much more). Single items measured social connection ("connected"), social disconnection ("lonely") and a single item measured positive feelings ("positive") in response to the daydream. Participants rated the valence of their daydream from 1(very negative) to 7 (very positive) and how fanciful their daydream was from 1 (completely realistic) to 7 (completely fanciful). Participants also 
rated the quality of the relationship between themselves and the most central other person involved in their daydream. Three items, based on previous research (Niven et al., 2012), were used to index relationship quality: participants rated their general feelings of closeness, liking, and trust toward that person on scales from 1 (not at all) to 7 (extremely). Items were averaged to create an overall score for relationship quality $(\alpha=0.90)$.

\section{Feelings from Environment}

Participants rated the extent to which they had felt "connected with others," "positive," and "negative" so far that day, or since their last signal on that day on scales from 1 (not at all) to 7 (a great deal).

\section{T1 and T2 Measures \\ Loneliness}

Loneliness was measured using the eight-item short-form of the UCLA Loneliness Scale (ULS-8; Hays and DiMatteo, 1987). Participants rated the extent to which they had felt socially isolated over the past 2 weeks (e.g., "Isolated from others") from 1 (never) to 4(always). Items were averaged to provide a score for loneliness, with higher scores indicating greater loneliness. Internal reliability was high at $\mathrm{T} 1(\alpha=0.89)$ and $\mathrm{T} 2(\alpha=0.91)$.

\section{Social Adaptation to University}

This was measured using the 20-item social adjustment subscale of the Student Adjustment to College questionnaire (SACQ; Baker and Siryk, 1989). Participants were asked to consider the "past 2 weeks" when indicating the extent to which several items indicating social adaptation (e.g., "I am very involved in social activities in university") apply to them from 1 (applies very closely to $m e$ ) to 9 (doesn't apply to me at all). Negatively worded items were reverse-scored and items were then averaged to create an overall score for social adaptation to university with higher scores indicating greater social adjustment. Internal reliability was high at T1 $(\alpha=0.93)$ and T2 $(\alpha=0.93)$.

\section{RESULTS}

\section{Response Rate}

Participants completed 3697 out of a possible 5768 responses corresponding to a $64 \%$ response rate. On these occasions, participants reported that they were currently daydreaming $64 \%$ of the time and $92 \%$ of these daydreams were social. Of the social daydreams during the study, $46 \%$ involved people before university, $48 \%$ involved people after university, and $6 \%$ involved some other category (e.g., an imaginary person, celebrity). Social daydreams showed a slight shift to after-university contacts during the later weeks: during E1, $47 \%$ of social daydreams involved people before university, $45 \%$ involved people after university, and $8 \%$ involved some other category; during E2, $45 \%$ of social involved people before university, 50\% involved people after university, and $5 \%$ involved some other category. The percentage of social daydreams in the present study is notably higher than other estimates (e.g., 71\%; Song and Wang, 2012). This fits well with the proposal that social daydreams become more frequent during times of social challenge. When participants were not daydreaming at the time of signaling, or if their current daydream was not social, then they reported on their last social daydream, which occurred on 1532 occasions (41\%). Current or last social daydreams (coded 0,1 ) did not show different associations to any of the experiencesampling dependent variables (i.e., the emotional content and outcomes of daydreaming, their fanciful nature, the relationship quality, and feelings from the environment did not differ according to whether daydreams were currently experienced or reported retrospectively). We interpret this as evidence that retrospective and in the moment reports of social daydreams were reported with similar levels of accuracy by participants.

Ninety-nine participants completed the T1 questionnaire (a $96 \%$ response rate); at this stage two participants had dropped out of the study because they had left university, and one participant could not continue owing to difficulty tracking daydreaming experience. Ninety-seven of the 99 participants who completed the T1 questionnaire also completed the T2 questionnaire (a total response rate of $94 \%$ ).

\section{Did the Emotional Outcomes and Content of Daydreams and Feelings from the Environment Change Over Time?}

To examine whether daydreams and feelings in general showed significant patterns of change over time, we examined the effect of time on each dependent variable from the experiencesampling measures. The data had a natural two-level structure (i.e., responses collected over a series of time-points nested within individuals) so data were analyzed by multi-level modeling (Hox, 2010) using the Mixed procedure in IBM SPSS v.21 software. We examined the effect of time on daydreaming and feelings separately for the first and second experiencesampling periods (E1 and E2). The within and between subjects variance of each dependent variable was partitioned by fitting random intercept and slope terms for each individual. Nonindependence of observations was modeled by fitting an autoregressive correlation structure (AR1) to level-1 residuals. Time since starting the study was tested as a fixed effect. Some participants began the study later than others so we created a variable representing lapsed time since starting university on commencing the study and entered this as a fixed effect in all models to control for its potential influence. Time since starting the study was non-significant in all models except for predicting how lonely participants' social daydreams made them feel during E1. Specifically, participants' who started the study later, had daydreams that made them feel less lonely during E1 $[B=-0.02, t(101)=-2.09$, $p=0.039]$.

Table 1 summarizes the effect of time on social daydreaming and feelings from the environment for E1 and E2. The first weeks of the study (E1) were not characterized by any significant patterns of change for the characteristics of daydreaming. For more general feelings from the environment, feelings of 
TABLE 1 | Fixed effects of time on daydreaming characteristics and feelings in general over E1 and E2.

\begin{tabular}{|c|c|c|c|c|c|c|c|c|c|c|c|c|}
\hline \multirow[b]{2}{*}{ Fixed effects } & \multicolumn{6}{|c|}{ E1 } & \multicolumn{6}{|c|}{ E2 } \\
\hline & $d f$ & $\beta$ & $B$ & SE & $t$ & ICC & $d f$ & $\beta$ & $B$ & SE & $t$ & ICC \\
\hline \multicolumn{13}{|c|}{ Emotional outcomes of daydreaming } \\
\hline Connected & 618 & 0.00 & -0.000327 & 0.00441 & -0.07 & 0.17 & 575 & 0.07 & 0.0125 & 0.00388 & $3.22^{* * *}$ & 0.28 \\
\hline Lonely & 585 & 0.01 & 0.00253 & 0.00471 & 0.54 & 0.22 & 573 & -0.07 & -0.0123 & 0.00412 & $-2.98^{* *}$ & 0.30 \\
\hline Positive & 592 & 0.02 & 0.00483 & 0.00497 & 0.97 & 0.18 & 571 & 0.03 & 0.00592 & 0.00431 & 1.37 & 0.23 \\
\hline \multicolumn{13}{|c|}{ Daydreaming content } \\
\hline Valence & 596 & 0.03 & 0.00756 & 0.00548 & 1.38 & 0.15 & 601 & 0.04 & 0.00711 & 0.0260 & 1.45 & 0.17 \\
\hline Fanciful & 612 & 0.03 & 0.00850 & 0.00608 & 1.40 & 0.23 & 534 & -0.06 & -0.0154 & 0.00593 & $-2.60^{* *}$ & 0.28 \\
\hline Relationship quality & 615 & 0.00 & -0.000375 & 0.00553 & -0.07 & 0.18 & 607 & 0.08 & 0.0168 & 0.00457 & $3.69 * * *$ & 0.25 \\
\hline \multicolumn{13}{|c|}{ Feelings from environment } \\
\hline Connectedness & 546 & -0.01 & -0.00166 & 0.00333 & -0.49 & 0.24 & 489 & 0.06 & 0.00777 & 0.00325 & $2.40^{*}$ & 0.35 \\
\hline Positive & 542 & -0.02 & -0.00330 & 0.00335 & -0.99 & 0.24 & 442 & 0.07 & 0.00898 & 0.00335 & $2.68^{* *}$ & 0.33 \\
\hline Negative & 528 & 0.06 & 0.00836 & 0.00358 & $2.33^{*}$ & 0.31 & 475 & -0.05 & -0.00736 & 0.00330 & $-2.23^{*}$ & 0.39 \\
\hline
\end{tabular}

SE, standard error. Time since starting university entered as a fixed effect in all models. ${ }^{*} p<0.05,{ }^{* *} p<0.01,{ }^{* * *} p<0.001$.

connection with others and feeling positive did not show significant patterns of change. However, feeling negative showed a significant and reliable increase during $\mathrm{E} 1[\beta=0.06$, $B=0.00836, t(428)=2.33, p=0.020,95 \% \mathrm{CI}[0.00132,0.0154]]$, suggesting that the first weeks of university may have been a time associated with increased negative emotion.

As expected, the pattern of change over time was substantially different for E2. Over time, participants' social daydreams made them feel significantly more connected $[\beta=0.07, B=0.0125$, $t(575)=3.22, p=0.001,95 \% \mathrm{CI}[0.00484,0.0201]]$ and less lonely $[\beta=-0.07, B=-0.0123, t(573)=-2.98, p=0.003,95 \% \mathrm{CI}[-$ $0.0204,-0.00418]]$, but not more positive $[\beta=0.03, B=0.00592$, $t(571)=1.37, p=0.170,95 \%$ CI $[0.00255,-0.0144]]$. Participants' social daydreams also became significantly less fanciful in content $[\beta=-0.06, B=-0.0154, t(534)=-2.60, p=0.009,95 \%$ $\mathrm{CI}[-0.0271,-0.00379]]$ and involved higher quality relationships $[\beta=0.08, B=0.0168, t(607)=3.69, p<0.001,95 \% \mathrm{CI}[0.00787$, $0.0258]]$; but did not become more positively valenced $[\beta=0.04$, $B=0.00711, t(601)=1.45, p=0.146,95 \%$ CI $[-0.00249$, 0.0167]]. Likewise, participants reported feeling in general significantly more connected with others $[\beta=0.06, B=0.00777$, $t(489)=2.40, p=0.017,95 \% \mathrm{CI}[0.00140,-0.0142]]$, more positive $[\beta=0.07, B=0.00898, t(442)=2.68, p=0.008,95 \%$ $\mathrm{CI}[0.00240,0.0156]]$ and less negative $[\beta=-0.05, B=-0.00736$, $t(475)=-2.23, p=0.026,95 \% \mathrm{CI}[-0.0138,-0.000867]]$ over time. We repeated these analyses for two subgroups: early study starters ( $<2$ weeks of starting university, $n=55$ ) and late starters ( $>2$ weeks of starting university, $n=48$ ). In line with the idea that the adaptive response takes time, effects were most evident for the late starter group during E2. We also observed additional effects for valence such that daydreams for late starters during E2 became more positive over time.

We also repeated these analyses considering the whole sampling period (i.e., 4 weeks). Consistent with the results for E2, over the whole study period, participants social daydreams made them feeling increasingly connected $[\beta=0.08, B=0.00771$, $t(63)=3.38, p<0.001,95 \%$ CI[0.00477, 0.0107]], less lonely $[\beta=-0.06, B=-0.00635, t(69)=-3.00, p=0.004,95 \% \mathrm{CI}[-$ $0.00954,-0.00317]]$, and involved higher quality relationships $[\beta=0.07, B=0.00822, t(63)=3.41, p=0.001,95 \% \mathrm{CI}[0.00464$, $0.0118]$ ]. In contrast to the results from E2 participants' social daydreams made them feel increasingly positive $[\beta=0.07$, $B=0.00718, t(64)=3.58, p=0.001,95 \% \mathrm{CI}[0.00389$, $0.0105]]$, the content of social daydreams became more positively valenced $[\beta=0.07, B=0.00704, t(60)=2.61, p=0.012$, $95 \% \mathrm{CI}[0.00335,0.0107]]$, but did not become less fanciful $[\beta=0.02, B=0.00320, t(72)=1.63, p=0.107,95 \% \mathrm{CI}[-$ $0.00108,0.00747]]$. In general, participants also reported feeling increasingly positive $[\beta=0.04, B=0.00254, t(63)=2.09$, $p=0.037,95 \% \mathrm{CI}[0.000186,0.00488]]$ and less negative $[\beta=-$ $0.04, B=-0.00324, t(63)=-2.50, p=0.015,95 \% \mathrm{CI}[-0.00569,-$ $0.000788]]$ but not more connected with others $[\beta=0.04$, $B=0.00264, t(52)=0.80, p=0.426,95 \% \mathrm{CI}[-0.000234$, $0.00505]]$ over the study period. Thus the results of the effect of time on social daydreaming and feelings also emerged over the study period, although examinations of E1 and E2 separately indicate that these effects occur, as predicted, later during the transition.

\section{Emotional Inertia}

We predicted that participants, who reported being currently less adjusted to university would show faster changes in the emotional outcomes of their social daydreams (i.e., low emotional inertia) than those who were more adjusted. Given that the social emotional outcomes (connected, lonely) of participants' daydreams increased significantly during E2, we were interested in examining the extent to which they might show resistance or susceptibility to change depending on levels of social adaptation at T1. Evidence for this would be provided by a significant crosslevel interaction between the autocorrelation of each dependent variable (i.e., the lag of the variables for connected and lonely) and levels of social adaptation (results are summarized in Table 2). 
TABLE 2 | Emotional inertia analyses for socio-emotional outcomes of social daydreaming during E2 with social adaptation at T1.

\begin{tabular}{|c|c|c|c|c|c|c|c|c|}
\hline Emotional outcome & Key variable & $-2 * L L$ & $-2 * \operatorname{LL} \Delta$ & $d f$ & Estimate (SE) & $p$ & $95 \% \mathrm{Cl}$ & ICC \\
\hline \multicolumn{9}{|l|}{ Connected } \\
\hline Fixed effects & Lag of connected & 5357.48 & - & 1760 & $0.04(0.02)$ & 0.075 & $-0.00,0.09$ & 0.26 \\
\hline Random effects & Lag of connected & 5337.22 & $20.25^{* * *}$ & 86 & $0.04(0.01)$ & 0.005 & $0.02,0.07$ & 0.03 \\
\hline Level-2 fixed effect & Social adjustment & 5314.46 & $22.76^{* * *}$ & 64 & $0.22(0.06)$ & 0.001 & $0.09,0.34$ & 0.48 \\
\hline Interaction & $\begin{array}{l}\text { Lag of connected*Social } \\
\text { adaptation }\end{array}$ & 5312.76 & 1.70 & 64 & $0.08(0.03)$ & 0.008 & $0.02,0.14$ & 0.44 \\
\hline \multicolumn{9}{|l|}{ Lonely } \\
\hline Fixed effects & Lag of lonely & 5540.30 & - & 1758 & $0.05(0.02)$ & 0.021 & $0.01,0.10$ & 0.27 \\
\hline Random effects & Lag of lonely & 5540.17 & 0.14 & 53 & $0.00(0.01)$ & 0.764 & $0.00,1.44$ & 0.00 \\
\hline
\end{tabular}

SE, standard error; LL, log likelihood. ${ }^{* * *} p<0.001$.

The fixed effects of the lag variables on feeling connected and lonely as an index of inertia were positive and significant demonstrating autocorrelation between adjacent time points. The addition of our level-2 predictor was justified by examining the improvement in model fit by allowing slopes as well as intercepts to vary. Improvement in model fit was only significant for the model predicting feeling connected but not lonely. We therefore only examined the cross-level interaction between social adaptation and the lag of connectedness which, as expected, was significant $[\beta=0.08, t(64)=2.72$, $p=0.008,95 \% \mathrm{CI}[0.02,0.14]]$. Equivalent results were obtained when the lag of connectedness was cluster mean centered $(\beta=0.07, p=0.024)$. See Hamaker and Grasman (2015) for a discussion of centering in inertia analyses. As shown in Figure 2, participants who were low (1SD below the mean), compared to high (1SD above the mean), in social adaptation showed lower levels of inertia. This suggests that participants who were less socially adapted to university showed less inertia for feelings of connection as a result of their social daydreams, indicative of an adaptive response.

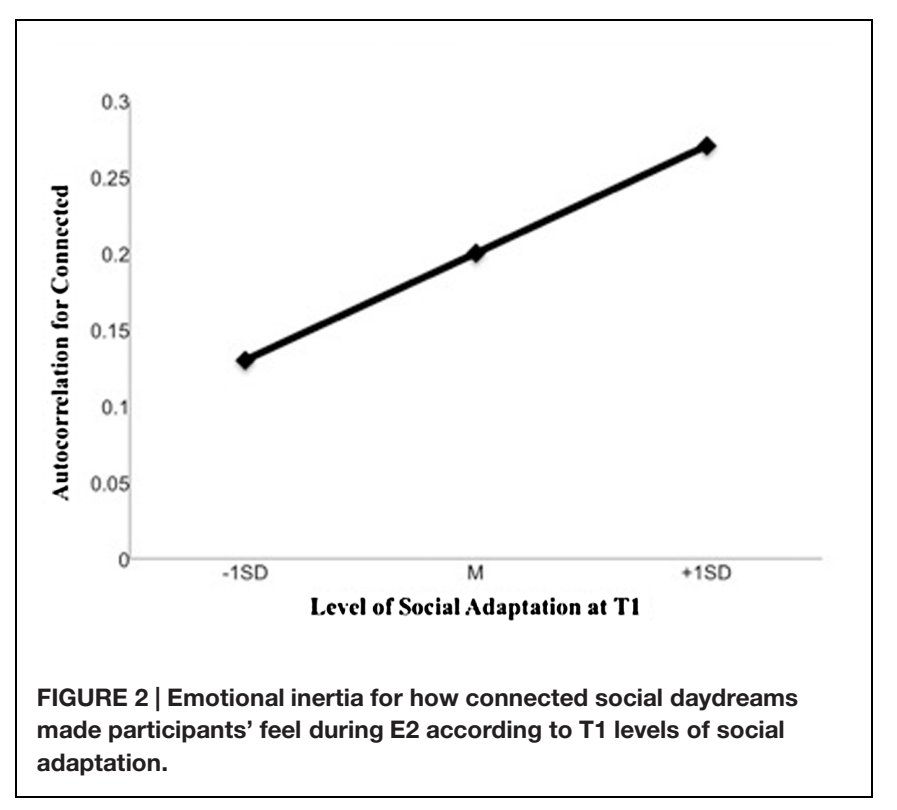

\section{Did Social Daydreaming Predict Loneliness and Social Adaptation to University?}

Given the significant patterns of change observed in social daydreaming during $\mathrm{E} 2$, we examined whether these daydreaming characteristics predicted later loneliness and social adaptation to university. These analyses required an examination of bottom-up effects (i.e., predicting level-2 outcomes from level-1). Traditional multi-level models do not allow level-2 variables as outcomes (only as predictors), which would not allow us to test, for example, whether loneliness at the end of the study (a level-2 variable) is predicted by daydreaming characteristics during the study (level-1 variables). To overcome this, we therefore used multi-level structural equation modeling (MSEM; Preacher et al., 2010) using Mplus software (Muthén et al., 1998-2011), which can accommodate level-2 variables as outcome variables and mediators. Mplus does not currently allow the modeling of autocorrelation by fitting an autoregressive correlation structure (Bolger and Laurenceau, 2013) so we entered the lag for each level-1 variable within the models (e.g., Totterdell et al., 2006).

\section{Loneliness}

We examined the effect of daydreaming during E2 on T2 loneliness, controlling for $\mathrm{T} 1$ loneliness in all models ( $\mathrm{T} 1$ loneliness significantly predicted T2 loneliness; all $\beta s>0.81$, all ps $<0.001)$. Results showed that T2 loneliness was negatively predicted by daydreams that made participants feel connected $(\beta=-0.16, S E=0.07, p=0.020,95 \% \operatorname{CI}[-0.30,-0.05])$ and positive $(\beta=-0.20, S E=0.08, p=0.010,95 \% \mathrm{CI}[-0.33,-0.07])$, and positively predicted by daydreams that made participants feel lonely $(\beta=0.13, S E=0.07, p=0.041,95 \% \mathrm{CI}[0.03,0.24])$. Likewise, T2 loneliness was negatively predicted by daydreams that were positively valenced ( $\beta=-0.24, S E=0.07, p=0.001$, $95 \% \mathrm{CI}[-0.36,-0.13])$ and involved high quality relationships $(\beta=-0.12, S E=0.06, p=0.042,95 \% \mathrm{CI}[-0.21,-0.02])$, but was positively predicted by fanciful daydreams $(\beta=0.12$, $S E=0.05, p=0.021,95 \% \mathrm{CI}[0.03,0.21])$. This indicates that participants were less lonely at T2 if their daydreams during E2 made them feel more connected, less lonely, and more positive, and their daydreams were less fanciful, more positively valenced and involved higher quality relationships. 


\section{Social Adaptation}

Using the same analytical procedure, we examined the effect of daydreams during E2 on T2 social adaptation to university controlling for $\mathrm{T} 1$ social adaptation ( $\mathrm{T} 1$ social adaptation significantly predicted T2 social adaptation in all models, $\beta s>0.25$, all $p s<0.05$, except when examining relationship quality where this relationship was marginal, $\beta=0.27, S E=0.14$, $p=0.062$ ). Unexpectedly, the social daydreams during E2 did not predict $\mathrm{T} 2$ social adaptation: social adaptation was not significantly predicted by the emotional outcomes of social daydreams (connected: $\beta=0.15, S E=0.32, p=0.642,95 \% \mathrm{CI}[-$ $0.38,0.67]$, lonely: $\beta=0.35, S E=0.33, p=0.292,95 \% \mathrm{CI}[-0.19$, $0.89]$, positive: $\beta=-0.12, S E=0.30, p=0.687,95 \% \mathrm{CI}[-0.60$, $0.37]$ ) or their characteristics (valence: $\beta=0.27, S E=0.27$, $p=0.312,95 \% \mathrm{CI}[-0.17,0.71]$, fanciful: $\beta=0.07, S E=0.22$, $p=0.738,95 \% \mathrm{CI}[-0.43,0.29]$, relationship quality: $\beta=0.03$, $S E=0.38, p=0.929,95 \% \mathrm{CI}[-0.59,0.67])$.

\section{Supplementary Mediation Analysis}

Given that social daydreams were significantly related to loneliness but had no direct effect on social adaptation, we wondered whether social daydreaming might indirectly influence social adaptation through its demonstrated effects on loneliness. To examine this, we constructed a series of multi-level mediation models to examine whether social daydreams during E2 had indirect effects on social adaptation via loneliness. In each model, we controlled for $\mathrm{T} 1$ loneliness and $\mathrm{T} 1$ social adaptation to university and included the lag of each associated level-1 variable. The results of our multi-level mediation analyses are summarized in Table 3.

In all models, lower levels of loneliness predicted greater social adaptation to university (i.e., path b: all $\beta s<-0.39$, all $p$ s $<0.001)$. Examination of paths $a$ and $c$ in each model (i.e., daydreaming predicting loneliness and social adaptation) largely reflects previous analyses that constructive daydreaming predicts less loneliness but not social adaptation. Note that the effects for how lonely daydreams make participants feel and relationship quality are now marginal and non-significant, respectively. Of critical interest were paths $a b$ (i.e., the indirect effects of daydreaming on social adaptation via loneliness), which were significant for daydreams that made participants feel more connected $(\beta=0.12, S E=0.06, p=0.047,95 \% \mathrm{CI}[0.02,0.22])$ and positive $(\beta=0.14, S E=0.06, p=0.033,95 \% \mathrm{CI}[0.03,0.24])$, marginally significant for daydreams that made participants feel less lonely $(\beta=-0.13, S E=0.07, p=0.077,95 \% \mathrm{CI}[-0.24$, $0.01])$, and were more positive in content $(\beta=0.16, S E=0.07$, $p=0.013,95 \% \mathrm{CI}[0.06,0.27])$, and less fanciful $(\beta=-0.19$, $S E=0.09, p=0.024,95 \% \mathrm{CI}[-0.35,-0.05])$. This suggests that although social daydreams did not exert direct effects on social adaptation, they had an indirect effect on social adaptation via their effect on loneliness.

\section{DISCUSSION}

The evidence from this experience-sampling study supports the idea that the characteristics of social daydreaming during an important life context (the transition to university) promote adjustment to social challenges. First, consistent with the notion of an adaptive, but delayed, response to environmental challenges in which daydreams become more constructive in nature over time, the characteristics of daydreams became more constructive in the later, rather than earlier, weeks of the study. In the early weeks of the transition, no reliable patterns of change were observed in participants' social daydreams but negative affect from the environment reliably increased during this time, indicating that the initial transition to university was a difficult period associated with negative feelings. In contrast, later study weeks were characterized by increasingly constructive social daydreaming over time; specifically, daydreams made participants feel more connected, less lonely, were less fanciful in nature and involved higher quality relationships. At the same time, participants also felt more connected with others, more positive, and less negative in general.

Second, participants who reported being less socially adapted to university showed faster changes in how connected their

TABLE 3 | Summary of multi-level mediation models examining the indirect effect of social daydreaming characteristics on social adaptation to university via loneliness.

\begin{tabular}{|c|c|c|c|c|c|c|c|c|c|c|c|c|}
\hline & \multicolumn{4}{|c|}{ Path a } & \multicolumn{4}{|c|}{ Path $c$} & \multicolumn{4}{|c|}{ Path $a b$} \\
\hline & $\beta$ & $S E$ & $p$ & $95 \% \mathrm{Cl}$ & $\beta$ & $S E$ & $p$ & $95 \% \mathrm{Cl}$ & $\beta$ & $S E$ & $p$ & $95 \% \mathrm{Cl}$ \\
\hline Connected & -0.37 & 0.18 & 0.044 & $-0.67,-0.07$ & 0.01 & 0.13 & 0.922 & $-0.21,0.23$ & 0.12 & 0.06 & 0.047 & $0.02,0.22$ \\
\hline Lonely & 0.39 & 0.21 & 0.063 & $0.05,0.73$ & -0.04 & 0.14 & 0.799 & $-0.27,0.20$ & -0.13 & 0.07 & 0.077 & $-0.24,-0.01$ \\
\hline Positive & -0.42 & 0.19 & 0.026 & $-0.73,-0.11$ & 0.00 & 0.12 & 0.991 & $-0.19,0.20$ & 0.14 & 0.06 & 0.033 & $0.03,0.24$ \\
\hline Fanciful & 0.60 & 0.25 & 0.017 & $0.19,1.01$ & 0.34 & 0.19 & 0.070 & $0.03,0.66$ & -0.19 & 0.09 & 0.024 & $-0.34,-0.05$ \\
\hline $\begin{array}{l}\text { Relationship } \\
\text { quality }\end{array}$ & -0.31 & 0.27 & 0.244 & $-0.76,0.13$ & -0.12 & 0.17 & 0.500 & $-0.40,0.17$ & 0.10 & 0.09 & 0.250 & $-0.04,0.25$ \\
\hline
\end{tabular}

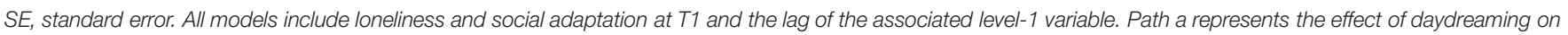

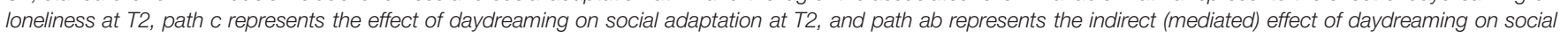
adaptation via loneliness. Path b (the effect of loneliness on social adaptation) is not represented here, but was positive and significant ( $p<0.001)$ in all models. 
daydreams made them feel than others; that is, they showed less evidence of emotional inertia in response their social daydreaming. High emotional inertia is considered an index of maladjustment (e.g., Kuppens et al., 2010) suggesting that the lack of inertia for connectedness observed in participants who were less adapted to university was indicative of a functional affective response. Low emotional inertia is likely to reflect the adaptive nature of emotions, which enable individuals to flexibly respond to environmental challenges. Evidence of low emotional inertia for a positive social emotion (connectedness), as a result of cognition (social daydreaming) in a dynamic context (adjustment to university) contributes to the growing literature on the dynamics of emotion and adjustment (e.g., Kuppens et al., 2012). Our results indicate that high inertia is not necessarily a pattern of emotion dynamics for those who are currently socially maladjusted. Rather, current social maladjustment may be characterized by low inertia when individuals are in the process of adjusting to social challenges, which is likely to be functional (c.f., Koval and Kuppens, 2012).

Third, positive social daydreaming characteristics predicted less loneliness. Specifically, participants were less lonely if their social daydreams made them feel more connected, less lonely, and more positive and their content was less fanciful, more positively valenced, and involved higher quality relationships. These findings are consistent with a growing body of research showing that certain kinds of social daydreaming may buffer against or counteract loneliness (Mar et al., 2012; Poerio et al., 2013, 2015a). However, the present study extends these findings by demonstrating that social daydreaming can have a socioemotional benefit over time during a naturally occurring period of social challenge.

Fourth, social daydreaming had an indirect effect on social adaptation to university via their influence on loneliness. Although we expected social daydreaming to directly predict social adjustment, this was not supported. However, supplementary mediation analyses showed indirect effects of daydreaming on social adaptation via loneliness for daydreams that made participants feel more connected, more positive, and less lonely and that were more positively valenced and less fanciful in content. These results suggest that social daydreaming may be especially linked to individuals' socio-emotional well-being (e.g., loneliness) which then impacts on cognitive evaluations of their social situation. It is also possible that social daydreaming may have a longer-term effect on cognitive well-being (e.g., life satisfaction) which was not captured in the current month-long study.

\section{Mechanisms Linking Social Daydreaming to Adjustment}

How does social daydreaming promote socio-emotional adjustment? Our findings point to the value of the regulation of social emotions (in particular feelings of social connection) for the process of adjustment. Over time, participants showed increases in feelings of interpersonal connection as a result of their social daydreams. Such an increase may be adaptive because it reflects a process whereby feelings of social connection contribute to more positive social interactions and the building of personal resources. Just as negative cognitions before and after social interactions (anticipatory and post-event processing, Clark and Wells, 1995) contribute to negative social interactions and the maintenance of social anxiety (e.g., Vassilopoulos, 2005; Taylor and Alden, 2011) we propose that an equivalent positive influence might be true for positive cognitions.

People who feel interpersonally connected after daydreaming may behave more positively toward others and have that positivity reciprocated in social interactions (Miller and Turnbull, 1986). Positive social interactions may lead to further feelings of social connection (Reis et al., 2000) and greater social resources (e.g., social support, interpersonal trust, and intimacy, Laurenceau et al., 1998; Burns et al., 2008; Kok and Fredrickson, 2010). Over time, the interplay between social interactions, social daydreaming and social emotions may contribute to greater socio-emotional functioning and greater socio-emotional well-being (e.g., less loneliness, flourishing).

In addition to emotional mechanisms, cognitive problemsolving processes might also explain, why social daydreaming promotes adjustment. Cognition can facilitate adjustment because it allows individuals to process important events, make sense of them and derive meaning (e.g., Taylor, 1983; Park, 2010). This involves problem-focused coping attempts that aid selfregulation and adjustment through the formation of concrete plans for action (Taylor et al., 1998). In particular, imagining past and possible future social interactions during social daydreams may facilitate learning, goal progress, problem-solving, and effective planning in the interpersonal domain (c.f., Baumeister and Masicampo, 2010).

Research on mental simulation and goals consistently shows that imagining the process, rather than the outcome, of goal achievement is associated with the successful pursuit of personal goals (Freund and Hennecke, 2015). That participants' social daydreams became less fanciful over time suggests that daydreams eventually become more concrete and based on actual or probable social interactions and situations following a transition. This shift could be indicative of a more processorientated approach to social problem-solving or planning which, in turn, may have facilitated later interpersonal behavior and reduced loneliness.

This view is consistent with evidence that daydreaming in general is associated with autobiographical planning (Baird et al., 2011) and social problem-solving (Ruby et al., 2013). However, whether or not social daydreams function in this manner for interpersonal goals is an open question. Research on the effect of mental simulation on goal achievement and coping has tended to focus on intrapersonal goals such as academic achievement or task performance (e.g., Pham and Taylor, 1999; Oettingen et al., 2000; Vasquez and Buehler, 2007) rather than on interpersonal goals such as the formation and maintenance of positive social relationships.

\section{Limitations and Future Directions}

A skeptical reader might question whether our results simply reflect the process of adjustment rather than contributing to it. 
Of course, daydreams will, in part, reflect one's current state of adjustment and the correlational nature of our investigation cannot unequivocally rule out reverse causation or third variable explanations. However, our analyses examining how social daydreams predicted later loneliness (and social adaptation via loneliness) controlled for these variables during the preceding 2 weeks thereby attenuating this concern. Whether or not social daydreams causally contributed to socio-emotional adjustment depends on whether imagination has a causal impact on later behavior and emotion. Various lines of research (reviewed in Baumeister et al., 2011) strongly suggest that conscious thought causes behavior albeit not immediately or directly, but the process by which social daydreams causally affect social behavior is a key question for future research. If this causal relationship is not supported, then we still have an epiphenomenon that is a potentially useful indicator of adjustment.

The present study only examined social daydreaming within one context of adjustment. We chose the university transition because it represents a stressful life event that is particularly associated with socio-emotional challenges. Whether similar findings can be observed during different life transitions should be addressed in future research. However, we expect that the theoretical rationale for why social daydreaming predicts adjustment would apply to various types of transitions where social goals and needs are pertinent (e.g., bereavement, marriage, divorce, parenthood). We also only examined social daydreaming at the start of a transition and could not therefore consider the anticipatory effects of daydreaming. However, anticipatory coping may occur before a stressful event, particularly when the event is expected, as in the case of the university transition (Aspinwall and Taylor, 1997). We would therefore expect social daydreaming in the weeks preceding a transition to be associated with adjustment as a form of pro-active coping (e.g., mental preparation for upcoming social interactions, thoughts about leaving established social networks, and expectations for the transition). Productive and unproductive social daydreaming in relation to an anticipated stressful event may be associated with later adjustment or maladjustment, respectively (e.g., Feldman and Hayes, 2005). In addition, it would have been informative to examine how dispositional characteristics of participants such as their pre-existing levels of depression or anxiety affected patterns of social daydreaming and moderated associations between daydreaming characteristics and loneliness. Given previous research linking dispositional affect to daydreaming (Marchetti et al., 2015) and the transition to university (Bewick et al., 2010), examining patterns of social daydreaming in potentially vulnerable participants could be particularly useful for examining for whom and when social daydreaming is associated with positive and negative outcomes in the context of life transitions and adjustment.

In addition to not examining social daydreaming prior to the university transition, we also only examined the early stages of that transition. This was based on the assumption that the first months would be especially likely to capture both the reaction and initial adaptive response to the transition. However, the potential effects of social daydreaming on adjustment may show different effects when examined over a longer time period. For example, we observed linear change in daydreaming characteristics over the latter weeks of the study, but longer sampling periods might reveal non-linear forms of change such as positive relationships that become weaker over time. It would be informative to examine the dynamics of social daydreaming over extended periods of time to adequately characterize the nature and form of change and how it relates to adjustment. Knowing the trajectory of social daydreaming in relation to adjustment could help to inform the timing of possible interventions directed at addressing social daydreaming to enhance socio-emotional wellbeing.

Despite these limitations, the present study offers a number of significant contributions to research and theory on daydreaming and adjustment. This is the first study to examine daydreaming repeatedly over time in the context of naturally occurring adjustment, showing that it is associated with an adaptive response. It is also the first study to examine the emotional dynamics of the outcomes of cognition by linking daydreaming with emotional inertia, which may be important for understanding the conditions under which cognition and emotion interact to predict adjustment. Finally, this study is the first systematic investigation of how the social content of thought is associated with adjustment. It is notable that previous research and theory on daydreaming and repetitive thinking have focused primarily on self-focused thoughts. Our research highlights the importance of exploring cognition that is focused on others, rather than just on the self, which is especially important given the amount of time spent thinking about others. Overall, we believe that this study represents the first step in developing an account of how imagining others facilitates adjustment and ultimately contributes to burgeoning evidence that, under the right conditions, letting the mind wander is functional.

\section{AUTHOR CONTRIBUTIONS}

GP conceived of and designed, the study in consultation with PT, L-ME, and EM. GP conducted the study and analyzed the data with assistance and contributions from PT. GP drafted the manuscript with contributions from PT, L-ME, and EM. All authors read and approved the final manuscript.

\section{FUNDING}

This research was supported by the Economic and Social Research Council [grant number ES-J500215-1] awarded to GP whilst at the University of Sheffield. 


\section{REFERENCES}

Andrews-Hanna, J. R., Kaiser, R. H., Turner, A. E. J., Reineberg, A. E., Godinez, D., Dimidjian, S., et al. (2013). A penny for your thoughts: dimensions of self-generated thought content and relationships with individual differences in emotional wellbeing. Front. Psychol. 4:900. doi: 10.3389/fpsyg.2013. 00900

Antrobus, J. S., Singer, J. L., and Greenberg, S. (1966). Studies in the stream of consciousness: experimental enhancement and suppression of spontaneous cognitive processes. Percept. Mot. Skills 23, 399-417. doi: 10.2466/pms.1966.23.2.399

Arthur, N., and Hiebert, B. (1996). Coping with the transition to post-secondary education. Can. J. Couns. Psychother. 30, 93-103.

Aspinwall, L. G., and Taylor, S. E. (1997). A stitch in time: self-regulation and proactive coping. Psychol. Bull. 121, 417-436. doi: 10.1037/0033-2909.121. 3.417

Baird, B., Smallwood, J., and Schooler, J. W. (2011). Back to the future: autobiographical planning and the functionality of mind-wandering. Conscious. Cogn. 20, 1604-1611. doi: 10.1016/j.concog.2011.08.007

Baker, R. W., and Siryk, B. (1989). Student Adaptation to College Questionnaire: Manual. Vancouver, WA: Western Psychological Services.

Baumeister, R. F., and Masicampo, E. J. (2010). Conscious thought is for facilitating social and cultural interactions: how mental simulations serve the animalculture interface. Psychol. Rev. 117, 945-971. doi: 10.1037/a0019393

Baumeister, R. F., Masicampo, E. J., and Vohs, K. D. (2011). Do conscious thoughts cause behavior? Annu. Rev. Psychol. 62, 331-361. doi: 10.1146/annurev.psych.093008.131126

Bewick, B., Koutsopoulou, G., Miles, J., Slaa, E., and Barkham, M. (2010). Changes in undergraduate students' psychological well-being as they progress through university. Stud. High. Educ. 35, 633-645. doi: 10.1097/ACM.0b013e3182a82266

Bitsika, V., Sharpley, C. F., and Rubenstein, V. (2010). What stresses university students: an interview investigation of the demands of tertiary studies. Aust. J. Guid. Couns. 20, 41-54. doi: 10.1375/ajgc.20.1.41

Bolger, N., and Laurenceau, J. P. (2013). Intensive Longitudinal Methods: An Introduction to Diary and Experience Sampling Research. New York City, NY: Guilford Press.

Bonanno, G. A. (2004). Loss, trauma, and human resilience: have we underestimated the human capacity to thrive after extremely aversive events? Am. Psychol. 59, 20-28. doi: 10.1037/0003-066X.59.1.20

Bower, J. E., Kemeny, M. E., Taylor, S. E., and Fahey, J. L. (1998). Cognitive processing, discovery of meaning, CD4 decline, and AIDS-related mortality among bereaved HIV-seropositive men. J. Consult. Clin. Psychol. 66, 979-986. doi: 10.1037/0022-006X.66.6.979

Burns, A. B., Brown, J. S., Sachs-Ericsson, N., Plant, E. A., Curtis, J. T., Fredrickson, B. L., et al. (2008). Upward spirals of positive emotion and coping: replication, extension, and initial exploration of neurochemical substrates. Pers. Individ. Dif. 44, 360-370. doi: 10.1016/j.paid.2007.08.015

Burwell, R. A., and Shirk, S. R. (2007). Subtypes of rumination in adolescence: associations between brooding, reflection, depressive symptoms, and coping. J. Clin. Child Adolesc. Psychol. 36, 56-65. doi: 10.1080/15374410709336568

Calhoun, L. G., Cann, A., Tedeschi, R. G., and McMillan, J. (2000). A correlational test of the relationship between posttraumatic growth, religion, and cognitive processing. J. Trauma. Stress 13, 521-527. doi: 10.1023/A:1007745627077

Christensen, T. C., Barrett, L. F., Bliss-Moreau, E., Lebo, K., and Kaschub, C. (2003). A practical guide to experience-sampling procedures. J. Happiness Stud. 4, 53-78. doi: 10.1023/A:1023609306024

Christoff, K., Ream, J. M., and Gabrieli, J. D. (2004). Neural basis of spontaneous thought processes. Cortex 40, 623-630. doi: 10.1016/S0010-9452(08)70158-8

Clark, D. M., and Wells, A. (1995). "A cognitive model of social phobia," in Social Phobia: Diagnosis, Assessment, and Treatment, eds R. Heimberg, M. Liebowitz, D. A. Hope, and F. R. Schneier (New York, NY: Guilford), 69-93.

Cutrona, C. E. (1982). "Transition to college: loneliness and the process of adjustment," in Loneliness: A Sourcebook of Current Theory, Research, and Therapy, eds L. A. Peplau and D. Perlman (New York, NY: Wiley), 291-309.

Deng, Y. Q., Li, S., and Tang, Y. Y. (2014). The relationship between wandering mind, depression and mindfulness. Mindfulness 5, 124-128. doi: 10.1007/s12671-012-0157-7
Edwards, R., Honeycutt, J. M., and Zagacki, K. S. (1988). Imagined interaction as an element of social cognition. West. J. Commun. 52, 23-45. doi: $10.1080 / 10570318809389623$

Ehlers, A., Mayou, R. A., and Bryant, B. (1998). Psychological predictors of chronic posttraumatic stress disorder after motor vehicle accidents. J. Abnorm. Psychol. 107, 508-519. doi: 10.1037/0021-843X.107.3.508

Eisma, M. C., Schut, H. A., Stroebe, M. S., Boelen, P. A., Bout, J., and Stroebe, W. (2014). Adaptive and maladaptive rumination after loss: a threewave longitudinal study. Br. J. Clin. Psychol. 54, 163-180. doi: 10.1111/bjc. 12067

Feldman, G., and Hayes, A. (2005). Preparing for problems: a measure of mental anticipatory processes. J. Res. Pers. 39, 487-516. doi: 10.1016/j.jrp.2004.05.005

Franklin, M. S., Mrazek, M. D., Anderson, C. L., Smallwood, J., Kingstone, A., and Schooler, J. W. (2013). The silver lining of a mind in the clouds: interesting musings are associated with positive mood while mind-wandering. Front. Psychol. 4:583. doi: 10.3389/fpsyg.2013.00583

Frederick, S., and Loewenstein, G. (1999). "Hedonic adaptation," in Well-Being: The Foundations of Hedonic Psychology, eds D. Kahneman, E. Diener, and N. Schwarz (New York, NY: Russell Sage Foundation), 302-329.

Freund, A. M., and Hennecke, M. (2015). On means and ends: the role of goal focus in successful goal pursuit. Curr. Dir. Psychol. Sci. 24, 149-153. doi: $10.1177 / 0963721414559774$

Giambra, L. M. (1995). A laboratory method for investigating influences of switching attention to task-unrelated imagery and thought. Conscious. Cogn. 4, 1-21. doi: 10.1006/ccog.1995.1001

Gilbert, D. T., Pinel, E. C., Wilson, T. D., Blumberg, S. J., and Wheatley, T. P. (1998). Immune neglect: a source of durability bias in affective forecasting. J. Pers. Soc. Psychol. 75, 617-638. doi: 10.1037/0022-3514.75.3.617

Gold, S. R., and Reilly, J. P. (1985). Daydreaming, current concerns and personality. Imagin. Cogn. Pers. 5, 117-125. doi: 10.2190/BR6K-0VUW-44GC-VLA4

Hamaker, E. L., and Grasman, R. P. (2015). To center or not to center? Investigating inertia with a multilevel autoregressive model. Front. Psychol. 5:1492. doi: 10.3389/fpsyg.2014.01492

Hays, R. D., and DiMatteo, M. R. (1987). A short-form measure of loneliness. J. Pers. Assess. 51, 69-81. doi: 10.1207/s15327752jpa5101_6

Holeva, V., Tarrier, N., and Wells, A. (2002). Prevalence and predictors of acute stress disorder and PTSD following road traffic accidents: thought control strategies and social support. Behav. Ther. 32, 65-83. doi: 10.1016/S00057894(01)80044-7

Honeycutt, J. M., Edwards, R., and Zagacki, K. S. (1989). Using imagined interaction features to predict measures of self-awareness: loneliness, locus of control, self-dominance, and emotional intensity. Imagin. Cogn. Pers. 9, 17-31. doi: 10.2190/02L8-1GMP-JV5C-JQ7X

Hox, J. J. (2010). Multilevel Analysis: Techniques and Applications. New York, NY: Routledge.

Hox, J. J., Maas, C. J., and Brinkhuis, M. J. (2010). The effect of estimation method and sample size in multilevel structural equation modeling. Stat. Neerl. 64, 157-170. doi: 10.1111/j.1467-9574.2009.00445.x

Hoyt, M. A., Stanton, A. L., Irwin, M. R., and Thomas, K. S. (2013). Cancerrelated masculine threat, emotional approach coping, and physical functioning following treatment for prostate cancer. Health Psychol. 32, 66-74. doi: $10.1037 / \mathrm{a} 0030020$

Ito, T., Tomita, T., Hasui, C., Otsuka, A., Katayama, Y., Kawamura, Y., et al. (2003). The link between response styles and major depression and anxiety disorders after child-loss. Compr. Psychiatry 44, 396-403. doi: 10.1016/S0010440X(03)00109-3

Kane, M. J., Brown, L. H., McVay, J. C., Silvia, P. J., Myin-Germeys, I., and Kwapil, T. R. (2007). For whom the mind wanders and when: an experience-smapling study of working memory and executive control in daily life. Psychol. Sci. 18, 614-621. doi: 10.1111/j.1467-9280.2007.01948.x

Kappes, H. B., Oettingen, G., and Mayer, D. (2012a). Positive fantasies predict low academic achievement in disadvantaged students. Eur. J. Soc. Psychol. 42, 53-64. doi: $10.1002 /$ ejsp. 838

Kappes, H. B., Schwörer, B., and Oettingen, G. (2012b). Needs instigate positive fantasies of idealized futures. Eur. J. Soc. Psychol. 42, 299-307. doi: 10.1002/ejsp.1854

Killingsworth, M. A., and Gilbert, D. T. (2010). A wandering mind is an unhappy mind. Science 330, 932. doi: 10.1126/science.1192439 
Klinger, E. (1990). Daydreaming: Using Waking Fantasy and Imagery for SelfKnowledge and Creativity. Los Angeles, CA: Tarcher.

Klinger, E. (1996). "Emotional influences of cognitive processing, with implications for theories of both," in The Psychology of Action: Linking Cognition and Motivation to Behavior, eds P. M. Gollwitzer and J. A. Bargh (New York, NY: Guilford Press), 168-189.

Klinger, E. (2009). "Daydreaming and fantasizing: thought flow and motivation," in Handbook of Imagination and Mental Simulation, eds K. D. Markman, W. M. P. Klein, and J. A. Suhr (New York, NY: Taylor and Francis), 225-239.

Klinger, E. (2013). Goal Commitments and the content of thoughts and dreams: basic principles. Front. Psychol. 4:415. doi: 10.3389/fpsyg.2013.00415

Klinger, E., Barta, S. G., and Maxeiner, M. E. (1980). Motivational correlates of thought content frequency and commitment. J. Pers. Soc. Psychol. 39, 1222-1237. doi: 10.1037/h0077724

Klinger, E., and Cox, W. M. (1987). Dimensions of thought flow in everyday life. Imagin. Cogn. Pers. 7, 105-128. doi: 10.2190/7K24-G343-MTQW-115V

Kok, B. E., and Fredrickson, B. L. (2010). Upward spirals of the heart: autonomic flexibility, as indexed by vagal tone, reciprocally and prospectively predicts positive emotions and social connectedness. Biol. Psychol. 85, 432-436. doi: 10.1016/j.biopsycho.2010.09.005

Koval, P., and Kuppens, P. (2012). Changing emotion dynamics: individual differences in the effect of anticipatory social stress on emotional inertia. Emotion 12, 256-267. doi: 10.1037/a0024756

Kuppens, P., Allen, N. B., and Sheeber, L. B. (2010). Emotional inertia and psychological maladjustment. Psychol. Sci. 21, 984-991. doi: $10.1177 / 0956797610372634$

Kuppens, P., Sheeber, L. B., Yap, M. B., Whittle, S., Simmons, J. G., and Allen, N. B. (2012). Emotional inertia prospectively predicts the onset of depressive disorder in adolescence. Emotion 12, 283-289. doi: 10.1037/a0 025046

Laurenceau, J. P., Barrett, L. F., and Pietromonaco, P. R. (1998). Intimacy as an interpersonal process: the importance of self-disclosure, partner disclosure, and perceived partner responsiveness in interpersonal exchanges. J. Pers. Soc. Psychol. 74, 1238-1251. doi: 10.1037/0022-3514.74.5.1238

Luhmann, M., Hofmann, W., Eid, M., and Lucas, R. E. (2012). Subjective well-being and adaptation to life events: a meta-analysis. J. Pers. Soc. Psychol. 102, 592-615. doi: $10.1037 / \mathrm{a} 0025948$

Manne, S., Ostroff, J. S., and Winkel, G. (2007). Social-cognitive processes as moderators of a couple-focused group intervention for women with early stage breast cancer. Health Psychol. 26, 735-744. doi: 10.1037/0278-6133. 26.6.735

Mar, R. A., Mason, M. F., and Litvack, A. (2012). How daydreaming relates to life satisfaction, loneliness, and social support: the importance of gender and daydream content. Conscious. Cogn. 21, 401-407. doi: 10.1016/j.concog.2011.08.001

Marchetti, I., Koster, E. H. W., Klinger, E., and Alloy, L. B. (2015). Spontaneous thought and vulnerability to mood disorders: the dark side of the wandering mind. Clin. Psychol. Sci. doi: 10.1177/2167702615622383 [Epub ahead of print].

Marchetti, I., Van de Putte, E., and Koster, E. H. W. (2014). Self-generated thoughts and depression: from daydreaming to depressive symptoms. Front. Hum. Neurosci. 8:131. doi: 10.3389/fnhum.2014.00131

Miller, D. T., and Turnbull, W. (1986). Expectancies and interpersonal processes. Annu. Rev. Psychol. 37, 233-256. doi: 10.1146/annurev.ps.37.020186. 001313

Mor, N., and Winquist, J. (2002). Self-focused attention and negative affect: a meta-analysis. Psychol. Bull. 128, 638-662. doi: 10.1037/0033-2909.128.4.638

Muthén, L. K., and Muthén, B. O. (1998-2011). Mplus User's Guide, 6th Edn. Los Angeles, CA: Muthén \& Muthén.

Niven, K., Holman, D., and Totterdell, P. (2012). How to win friendship and trust by influencing people's feelings: an investigation of interpersonal affect regulation and the quality of relationships. Hum. Relat. 65, 777-805. doi: $10.1177 / 0018726712439909$

Oettingen, G., Hönig, G., and Gollwitzer, P. M. (2000). Effective self-regulation of goal attainment. Int. J. Educ. Res. 33, 705-732. doi: 10.1016/S08830355(00)00046-X

Oettingen, G., and Wadden, T. A. (1991). Expectation, fantasy, and weight loss: is the impact of positive thinking always positive? Cogn. Ther. Res. 15, 167-175. doi: 10.1007/BF01173206
Park, C. L. (2010). Making sense of the meaning literature: an integrative review of meaning making and its effects on adjustment to stressful life events. Psychol. Bull. 136, 257-301. doi: 10.1037/a0018301

Pham, L. B., and Taylor, S. E. (1999). From thought to action: effects of process-versus outcome-based mental simulations on performance. Pers. Soc. Psychol. Bull. 25, 250-260. doi: 10.1177/0146167299025 002010

Poerio, G. L., Totterdell, P., Emerson, L., and Miles, E. (2015a). Helping the heart grow fonder during absence: daydreaming about significant others replenishes connectedness after induced loneliness. Cogn. Emot. doi: 10.1080/02699931.2015.1049516 [Epub ahead of print].

Poerio, G. L., Totterdell, P., Emerson, L. M., and Miles, E. (2015b). Love is the triumph of the imagination: daydreams about significant others are associated with increased happiness, love and connection. Conscious. Cogn. 33, 135-144. doi: 10.1016/j.concog.2014.12.011

Poerio, G. L., Totterdell, P., and Miles, E. (2013). Mind-wandering and negative mood: does one thing really lead to another? Conscious. Cogn. 22, 1412-1421. doi: 10.1016/j.concog.2013.09.012

Preacher, K. J., Zyphur, M. J., and Zhang, Z. (2010). A general multilevel SEM framework for assessing multilevel mediation. Psychol. Methods 15, 209-233. doi: $10.1037 / \mathrm{a} 0020141$

Reis, H. T., Sheldon, K. M., Gable, S. L., Roscoe, J., and Ryan, R. M. (2000). Daily well-being: the role of autonomy, competence, and relatedness. Pers. Soc. Psychol. Bull. 26, 419-435. doi: 10.1177/0146167200266002

Robinson, M. S., and Alloy, L. B. (2003). Negative cognitive styles and stressreactive rumination interact to predict depression: a prospective study. Cogn. Ther. Res. 27, 275-291. doi: 10.1023/A:1023914416469

Ruby, F. J., Smallwood, J., Sackur, J., and Singer, T. (2013). Is self-generated thought a means of social problem solving? Front. Psychol. 4:962. doi: 10.3389/fpsyg.2013.00962

Segerstrom, S. C., Eisenlohr-Moul, T. A., Evans, D. R., and Ram, N. (2015). Repetitive thought dimensions, psychological well-being, and perceived growth in older adults: a multilevel, prospective study. Anxiety Stress Coping 28, 287-302. doi: $10.1080 / 10615806.2014 .947285$

Segerstrom, S. C., Roach, A. R., Evans, D. R., Schipper, L. J., and Darville, A. K. (2010). The structure and health correlates of trait repetitive thought in older adults. Psychol. Aging 25, 505-515. doi: 10.1037/a0019456

Segerstrom, S. C., Stanton, A. L., Alden, L. E., and Shortridge, B. E. (2003). A multidimensional structure for repetitive thought: what's on your mind, and how, and how much? J. Pers. Soc. Psychol. 85, 909-921. doi: 10.1037/00223514.85.5.909

Seli, P., Cheyne, J. A., Xu, M., Purdon, C., and Smilek, D. (2015). Motivation, intentionality, and mind wandering: implications for assessments of taskunrelated thought. J. Exp. Psychol. Learn. Mem. Cogn. 41, 1417-1425. doi: $10.1037 / x l m 0000116$

Shaver, P., Furman, W., and Buhrmester, D. (1985). "Transition to college: network changes, social skills, and loneliness," in Understanding Personal Relationships: An Interdisciplinary Approach, eds S. Duck and D. Perlman (London: Sage Publications), 193-219.

Singer, J. L. (1966). Daydreaming: An Introduction to the Experimental Study of Inner Experience. New York, NY: Random House.

Smallwood, J., and Andrews-Hanna, J. (2013). Not all minds that wander are lost: the importance of a balanced perspective on the mind-wandering state. Front. Psychol. 4:441. doi: 10.3389/fpsyg.2013.00441

Smallwood, J., and Schooler, J. W. (2015). The science of mind wandering: empirically navigating the stream of consciousness. Annu. Rev. Psychol. 66, 487-518. doi: 10.1146/annurev-psych-010814-015331

Song, X., and Wang, X. (2012). Mind wandering in Chinese daily lives: an experience sampling study. PLoS ONE 7:e44423. doi: 10.1371/journal.pone.0044423

Stawarczyk, D., Majerus, S., and D'Argembeau, A. (2013). Concern-induced negative affect is associated with the occurrence and content of mindwandering. Conscious. Cogn. 22, 442-448. doi: 10.1016/j.concog.2013. 01.012

Stawarczyk, D., Majerus, S., Maj, M., Van der Linden, M., and D'Argembeau, A. (2011). Mind-wandering: phenomenology and function as assessed with a novel experience sampling method. Acta Psychol. (Amst) 136, 370-381. doi: 10.1016/j.actpsy.2011.01.002 
Taylor, C. T., and Alden, L. E. (2011). To see ourselves as others see us: an experimental integration of the intra and interpersonal consequences of selfprotection in social anxiety disorder. J. Abnorm. Psychol. 120, 129-141. doi: $10.1037 / \mathrm{a} 0022127$

Taylor, S. E. (1983). Adjustment to threatening events: a theory of cognitive adaptation. Am. Psychol. 38, 1161-1173. doi: 10.1037/0003-066X.38.11.1161

Taylor, S. E., Pham, L. B., Rivkin, I. D., and Armor, D. A. (1998). Harnessing the imagination: mental simulation, self-regulation, and coping. Am. Psychol. 53, 429-439. doi: 10.1037/0003-066X.53.4.429

Totterdell, P., Wood, S., and Wall, T. (2006). An intra-individual test of the demands-control model: a weekly diary study of psychological strain in portfolio workers. J. Occup. Organ. Psychol. 79, 63-84. doi: 10.1348/0 $96317905 X 52616$

Vasquez, N. A., and Buehler, R. (2007). Seeing future success: does imagery perspective influence achievement motivation? Pers. Soc. Psychol. Bull. 33, 1392-1405. doi: 10.1177/0146167207304541

Vassilopoulos, S. P. (2005). Anticipatory processing plays a role in maintaining social anxiety. Anxiety Stress Coping 18, 321-332. doi: 10.1080/1061580 0500258149
Wang, L., Hamaker, E. L., and Bergman, C. S. (2012). Investigating inter-individual difference in short-term intra-individual variability. Psychol. Methods 17, 567-581. doi: 10.1037/a0029317

Watkins, E. R. (2008). Constructive and unconstructive repetitive thought. Psychol. Bull. 134, 163-206. doi: 10.1037/0033-2909.134.2.163

Conflict of Interest Statement: The authors declare that the research was conducted in the absence of any commercial or financial relationships that could be construed as a potential conflict of interest.

The reviewer, Eve-Marie Blouin-Hudon, and handling Editor declared their shared affiliation, and the handling Editor states that the process nevertheless met the standards of a fair and objective review.

Copyright (C) 2016 Poerio, Totterdell, Emerson and Miles. This is an open-access article distributed under the terms of the Creative Commons Attribution License (CC BY). The use, distribution or reproduction in other forums is permitted, provided the original author(s) or licensor are credited and that the original publication in this journal is cited, in accordance with accepted academic practice. No use, distribution or reproduction is permitted which does not comply with these terms. 